\title{
SWOT Analysis of Tourism Development in West Scenic Area of Changbai Mountain and Its Countermeasure Research
}

\author{
Liguang Zhao \\ School of Taxation \\ Jilin University of Finance and Economics \\ Changchun 130117
}

\author{
Mingju Liu \\ Yatai School of Business \\ Jilin University of Finance and Economics \\ Changchun, China 130117
}

\author{
Yumei Yao \\ Yatai School of Business \\ Jilin University of Finance and Economics \\ Changchun, China 130117
}

\begin{abstract}
Located in northeast China, Changbai Mountain is one of the ten famous mountains of China, referring to the national $4 \mathrm{~A}$ level scenic area. It is divided into the scenic areas in the north, west and south. Although the west scenic area in Changbai Mountain starts late in development, it has advantaged natural resources. Nowadays, with the increase of travel demand, west scenic area in Changbai Mountain develops vigorously on the principle of "Protection First". SWOT analysis is carried out and countermeasures are proposed for tourism development of west scenic area in Changbai Mountain.
\end{abstract}

Keywords-west scenic area of Changbai Mountain; tourism industry; SWOT analysis

\section{INTRODUCTION TO WEST SCENIC AREA IN CHANGBAI MOUNTAIN}

\section{A. Geographical Location of West Scenic Area in Changbai Mountain}

As a world-famous tourist attraction, Changbai Mountain locates in the southeast of Jilin Province in northeast China. It is the source of three rivers, namely Tumen River, Yalu River and Songhua River. Changbai Mountain is rated as 5A level scenic spot by the National Tourism Administration. It is divided into north, west and south scenic areas.

The west scenic area in Changbai Mountain locates in Songjianghe Town, Fusong County, Baishan City of Jilin Province. Compared with north and south scenic areas, the volcanic landscape is more spectacular and gorgeous. Because the development of west scenic area is later than that of north scenic area, there are fewer artificial buildings. It still retains the original natural scenery which makes

Fund program: National Natural Science Foundation of China (project number: 41401146); Science and Technology Development Project in Jilin Province (20150204NY); Project of Education Department in Jilin Province (JJKH20170140SK). people enjoy themselves so much as to forget to leave.

\section{B. Tourism Resources of West Scenic Area in Changbai Mountain}

The west scenic area in Changbai Mountain has very rich tourism resources because of the existence of unique volcanic landform. Changbai Mountain has Crater Lake with the largest area, the highest altitude and the deepest depth in our country. The scenery around Tianchi is more miraculous. Continuous peaks surround the magnificent Tianchi, forming breathtaking scenery. West scenic area in Changbai Mountain is divided into four distinct landscape belts from top to bottom, including alpine tundra landscape belt, Yuehua forest landscape belt, coniferous forest landscape belt and mixed broadleaf-conifer forest landscape belt. Traveling by bus from bottom to top, tourists can enjoy four different landscape belts and green trees and snow in several hours and have a panoramic view. West scenic area in Changbai Mountain is honored as "Natural Gene Pool", deserving the reputation it enjoys. Except for the fascinating high mountains, west scenic area in Changbai Mountain also has Jinjiang Canyon, which is praised as "natural volcanic lava bonsai garden" with spectacular scenery and flow path of seventy kilometers.

\section{SWOT ANALYSIS ON WEST SCENIC AREA OF CHANGBAi MOUNTAIN}

\section{A. Strengths of the Development in West Scenic Area of Changbai Mountain}

1) The original landscape is retained and it has unique vertical landscape belts: Located in Northeast China Region with circumpolar latitude, Changbai Mountain is the highest mountain chain with large altitude intercept, so it forms the scene of multiple seasons in one mountain that "when 
flowers have faded in the plain, peach blossoms in the mountain begin to be in full bloom. It has broad-leaved forest belt, mixed broadleaf-conifer forest belt, coniferous forest belt and alpine tundra belt. The obvious altitude difference also makes the vertical distribution of plants in Changbai Mountain obvious.

It is scarce in worldwide that Changbai Mountain has rich and complete natural ecosystems and natural vertical distribution belt of plants. The unique and superior natural landscape is strength of Changbai Mountain.

2) Unique volcanic landform: The volcano in west scenic area of Changbai Mountain is a giant composite volcanic cone formed by alkaline rock. Activities of cenozoic volcano in Changbai Mountain is frequent and has erupted for many times. The 133 square kilometers of basaltic lava plateau and platform form the ridge of Changbai Mountain.

The long-term violent volcanic activities form giant composite volcanic cone, which is the main body of volcano in Changbai Mountain. After researching the time of volcanic eruption and rocks on Changbai Mountain, many geologists think the volcano on Changbai Mountain is a dormant active volcano and may erupt again in the future. Therefore, it has great scientific significance to research mechanism of volcanic activities in Changbai Mountain, magmatic evolution and disasters caused by volcanic eruption.

Changbai Mountain has the Crater Lake with the highest altitude and largest area in China-the Changbaishan Tianchi. The green and clear Tianchi just like a jade is surrounded by peaks in Changbai Mountain. But Tianchi is mist-shrouded. Only lucky tourists can see the Changbaishan Tianchi clearly.

On the volcanic lava platform between the Changbaishan Tianchi and the Wangtian'e volcano locates Jinjiang Canyon, which is called as "the First Canyon in Changbai Mountain". The deep and serene Jinjiang Canyon with lambdoid distribution is formed by erosion of Jinjiang water in south of Xiaobai Mountain of the main peak of Changbai Mountain. The geological movement, erosion of Jinjiang water for thousands of years and weathering forms the plateau volcanic canyon landform with the depth of more than one hundred meters and the largest scale in China. In Jinjiang Canyon, rocks are lively and vivid after "sculpture". Some resembles people and some resembles animals. The peculiarlooking rocks and flowing Jinjiang River forms the unique and attractive landscape in Changbai Mountain.

3) It is well-known and attracts tourists at home and abroad: As the highest mountain chain in Northeast Asian region, Changbai Mountain is honored as one of the ten famous mountains in China, referring to a national nature reserve. Chinese Korean nationality and Manchu originate here. In 1980, Changbai Mountain was listed in the international "Man and Biosphere Reserve" by UNESCO, referring the first batch of area in China listed in it. In 1992, it was rated as the international A level nature reserve by
WWF. Changbai Mountain is renowned worldwide and is rated as one of the world's three best water sources. The other two are Alps and Caucasus Mountains.

4) The government strongly support the development of local tourism: In June 2005, the People's Government of Jilin Province issued the Notice on Establishment of Committee in Protection, Development and Management of Changbai Mountain in Jilin Province and established this committee which represents the provincial government to lead and manage economic, social and administrative affairs and natural resources in the area in accordance with law. Meanwhile, the management committee of Changbai Mountain is treated and managed by Jilin Province according to the standard of city in province. The management committee of Changbai Mountain is the department directly under the government of Jilin Province and has high administrative level. It provides administrative guarantee to intensify the protection of Changbai Mountain, accelerate the development of competitive tourist industry, sort out the relationship and realize the unified planning, protection, development and management of Changbai Mountain.

5) Regional advantages: Jilin Province located in northeast China has very abundant tourism resources and fifty-nine landscape types. There are thirty-six types of tourism resources related to ice and snow, natural ecology, folk culture and frontier in Changbai Mountain. Six tourist lines exist in Jilin Province, including the lines from Changchun to Jilin, Baicheng to Changchun to Jilin to Yanji, Tonghua to Baishan to Changbai Mountain to Yanji, five lines of which include Changbai Mountain as the destination.

\section{B. Weaknesses of the Development in West Scenic Area of Changbai Mountain}

1) Tourism products are simple and insufficient: Most tourism products in Changbai Mountain as the main destination focus on sightseeing tour in Changbai Mountain. Products have simple and insufficient structure. It lacks long-term tourism products like vocation products. Therefore, tourists often choose sightseeing tour in Changbai Mountain for one to two days. The short duration of stay makes the absence of tourist consumption. Towns surrounding the Changbai Mountain scenic area are backward and fail to attract tourists and acquire growth of consumption.

2) Scenic area fails to get efficient protection: West scenic area of Changbai Mountain has late and immature development. So far, the visitor route in it has had no clear planning and is nonstandard, so that tourists fail to tour according to the correct route. For example, tourists tread to make new roads and park randomly and destroy vegetation. They break the harmonious landscape, disturb wildlife in west scenic area and destroy their habitat and source of food. The randomness of tourists also damages the natural scenic area to some extent. 
3) The obvious seasonal and regional difference contributes to big gap in number of tourists: Each tourist attraction has seasonal characteristics. The number of tourists, income and inputs of services differ in slack and peak seasons. It is particularly obvious in Changbai Mountain scenic area. The peak tourist season is summer from June to August in every year. The number of tourists in Changbai Mountain accounts for more than 60 percent that of the whole year. The large quantity variance makes the tourist number in Changbai Mountain scenic area is too large, the inputs of services are behind requirement and tourism quality of tourists lowers in peak season. In slack season, the tourist number is insufficient and the service infrastructure has non-occupation, causing wasting of resources and increasing operating costs.

Furthermore, the Changbai Mountain scenic area has vast area. At present, the scenic areas developed include north, south and west scenic areas. North scenic area of Changbai Mountain is the main destination of visitor. The number of tourists accounts for more than 70 percent of the total number.

4) Lack advanced consciousness of tourism marketing: Although Changbai Mountain has luxuriant tourism resources and tourism products in ecological tourism, outdoor exercise, leisure and recreation and culture, because of the absence of advanced and effective marketing methods for tourism products, tourists only know Tianchi and think the sole purpose is to visit Tianchi. However, Changbai Mountain has abundant tourism resources all the year round. Tourists' narrow understanding of Changbai Mountain leads to wasting of resources in slack season. People don't know many spectacular landscapes. Tianchi receives excessive tourists in peak season so it causes serious ecological damage to Tianchi.

5) It has imperfect infrastructure and inconvenient traffic: Traffic is important in a tourist attraction. Without convenient traffic, it is difficult to attract large numbers of tourists. It can only be "a fabled abode of immortals" even though it has the best scenery. Changbai Mountain has remote location in the southeast of Jilin Province. The economic development level in towns is backward and the road traffic needs improvement. Tourists get lost and cannot find the destination easily. It will cause traffic jam in peak season. Because the town has small scale and backward economy and the public transport in it doesn't get development, it causes difficulties for tourists who fail to realize self-driving travel and loses these tourists.

The infrastructure construction in scenic area is imperfect. Tourists cannot get satisfactory service in clothing, food, accommodation and transportation. Because the economic development level in surrounding area is low, no high quality accommodations and restaurants exist, so it fails to attract tourists to stay for a long time. Besides, the absence of facilities in shopping and entertainment cannot stimulate consumption of tourists. In the scenic area, the service facilities are poor and the system to guide visitors, medical system and sanitation system are imperfect. Some tourists with special requirements cannot get good service. It may let tourists do not want to tour again here and fails to attract other tourists.

\section{Opportunities of the Development in West Scenic Area of Changbai Mountain}

1) Economic development and national demand: Since the reform and opening up, the economic development of our country is increasingly rapid. After solving the problem of food and clothing, people pay more and more attention to requirements of culture, leisure and recreation. Many residents relax through traveling on the weekend and vacations. An increasing number of people pursue travel experience of higher quality instead of the low quality traveling of "sleep when they get on and go to stool when they get off'. Behaviors like littering in travel destination are infrequent. People have increasingly high demands for tourism products. It brings opportunities for tourism of Changbai Mountain.

2) National policy support: Tourism development stimulates domestic demand. Attentions have been paid to rapid development of tourist industry. As "one of the famous mountains" in our country, Changbai Mountain is distinctly important tourism resource. Therefore, governments at all levels attach special importance to Changbai Mountain. Policies and norms create unprecedented excellent environment and opportunities for better development of Changbai Mountain. In the past, most people travel in China's South-East coastal areas. Now, the northeast China becomes one of the tourist destinations. The rapid development of tourist industry in northeast China drives the development of Changbai Mountain.

3) Vigorous development of traffic: Traffic is important for tourist industry. Nowadays, the Changbaishan Airport has been built, radiating the passenger source of Changbai Mountain to more extensive areas like provinces in the southeast, Asia even the world. The development of airport, railway, highway and public transport vigorously promotes the development of tourist industry in Changbai Mountain.

\section{Threats of the Development in West Scenic Area of Changbai Mountain}

1) Ecosystem will be destroyed: So far, Changbai Mountain has kept the original natural landscape to a large extent. With the rapid development of tourist industry, the excessive development of tourism products, the speed and scale of protection and maintenance cannot keep up with the development speed. The original ecology suffers from excessive human intervention. It may cause the disorder even destruction of ecosystem of Changbai Mountain. The habitat of rare species in Changbai Mountain will be damaged. It may cause species extinction.

2) Instability of tourist economy: Tourist economy appears when the basic economic development reaches high level. Tourism is instable and fragile. Tourist economy will 
be influenced by many factors. Economic factor, political factor, natural factor, cultural factor and emergencies will cause great impact on tourist industry. So tourist economy will fluctuate greatly.

\section{COUNTERMEASURES OF TOURISM DEVELOPMENT IN WEST SCENIC AREA OF CHANGBAI MOUNTAIN}

\section{A. Maintenance of Old Scenic Spots in West Scenic Area of Changbai Mountain}

1) Maintain the original natural ecological landscape: The development of west scenic area of Changbai Mountain should adhere to the principle of natural protection first to protect the remains of volcanic geological scenery and complete original natural landscape. The west scenic area with volcano in Changbai Mountain is open in recent years. To realize the principle of protection and development, it is necessary to develop through dividing zones. For example, the core conservation area is only for organizational scientific investigation and exploration instead of large scale development. Tourists are forbidden to enter zones from north Jinjiang River to south Jinjiang River, and the bottom of north Jinjiang canyon where facilities shouldn't be built. Obvious signboard should be set volcanic geological section to warn tourists to visit protectively and completely eradicate man-made sabotage.

Therefore, fixed route should be determined as soon as possible to prevent the destruction of natural landscape. Because of the different types of tourism resources such as land scenery, water area landscape and plants landscape, it needs further general investigation and evaluation to reasonably make use of resources. The distances of scenic sports are different. Visitor routes can be set according to different requirements. Scientific, normative and correct tour descriptions are set in scenic sports. In scenic spots with ancient and famous trees, tour scope must be clear to forbid climbing and breaking off tree branches. Otherwise, the consequence is unthinkable. Fixed sites to stack trash are designed to prevent pollution.

2) Strengthen management and training of employees to improve service quality: Tourist industry is an important part of service industry. Except for tourism resources, service is of vital importance to tourist industry. The core of service is people. The management and training of service staff is the key to improve service quality. Only the improvement of service quality makes for the maintenance of the original environment. Job specification of employees should be established to make the service of employees systematized and normative and form high standard service quality. Plan of talent training should be formulated. Professional tour guides must be familiar with scenic sports, geology and landform, history, culture and infrastructure of Changbai Mountain. They should be amiable with good communicative competence and high quality. In adventure tourism, coaches for specialized guidance, assistant and commissioners and health workers to deal with the sudden accidents should be provided. Service staff in areas with accommodation, catering, shopping and entertainment facilities have unified service standard. Planning talents should be trained to give advice and suggestions for the development and innovation of Changbai Mountain scenic area and strive to construct the international first-class scenic area.

\section{B. Develop New Scenic Spots in West Scenic Area of Changbai Mountain}

1) Develop adventure tourism in west scenic area: Pedestrianism. It means passing through by walk through following the route. Tourists have to pass through plain, peak, canyon, cliff and water. The west scenic area of Changbai Mountain has diversified geology and landform. Volcano, canyon and waterfall can stimulate tourists to face the difficulty and explore bravely.

Drift, river tracing and ice climbing. The Jinjiang River and Jinjiang Waterfall in west scenic area of Changbai Mountain have advantaged conditions for tourists to carry out adventure tourism. In summer, drift is a popular outdoor exercise. In blistering summer day, tourists can snatch a little leisure from a busy life to come to the valley where the cool breeze is blowing, and drift leisurely. The river water in different sections of Jinjiang River in Changbai Mountain is different. Tourists can float downstream or upstream, or on the rip current.

Jinjiang River can come into play both in summer and winter. In winter, the air temperature of Changbai Mountain drops suddenly. Jinjiang River and waterfall will freeze. The Jinjiang waterfall that becomes an ice wall is suitable for visitors to climb.

Prompt drop and free climbing. Jinjiang Canyon is deep and magnificent and has cliff, suitable for prompt drop and free climbing.

Skiing. The quality of ice and snow on Changbai Mountain is very good. The terrain environment is very suitable for skiing. Alpine skiing of high difficulty can carry out on steep hill for professionals.

Diversified outdoor activities consist of the thrilling adventure tourism, which attracts fans who ardently love extreme sports and lets more people appreciate the charm of it.

2) Develop tourism with theme culture in west scenic area: Tourism with folk culture. Changbai Mountain is the birthplace of Chinese Korean nationality and Manchu, the language, diet, clothing, tradition and folk custom of which are attractive. The theme tourism according to characteristics of Chinese Korean nationality and Manchu will attract large numbers of tourists who love the culture. It is distinctly important to experience folk custom and charm of exotic culture. Besides, the development and popularization of diet and clothing will stimulate the consumption in Changbai Mountain scenic area and drive the development of scenic area and surrounding towns. 
Red tourism. It is very popular in recent years. In Changbai Mountian, anti-Japanese warriors in northeast China represented by General Yang Jingyu leave many sagas, which are important resources for red tourism.

Tourism with theme of the novel. With the popularization of the adventure novel Time Raiders, as a key place in it, Changbai Mountain takes the breath of fans of the novel away. The tourism with theme of the novel can attract many tourists who love novels and yearn for traveling in Changbai Mountain and show the innovative attitude.

3) Develop tourism of scientific investigation in west scenic area: The unique volcanic geology and abundant and various ecological resources in west scenic area of Changbai Mountain attract people to explore further. Tourism products related to scientific investigation for children and teenagers can be provided. Parents and teachers can lead children to visit volcano, rock, the largest Crater Lake, and rare protected animals like Manchurian tiger, sika deer and sable, and Yue birch, in order to broad the horizon of teenagers.

4) Develop vacation tour in west scenic area: The west scenic area of Changbai Mountain depends on volcano and high quality hot spring, and the flood icing praised as one of the world's three best water sources. Hot spring and flood icing can relieve people's pressure. We should vigorously develop hot-spring resort and flood icing experience zone to attract tourists and let them stay longer. It will stimulate consumption and better develop the Changbai Mountain.

\section{CONCLUSION}

Changbai Mountain has superior geographical conditions. Although the west scenic area in Changbai Mountain starts late in development, it has advantaged natural resources. Because of the unsound infrastructure and the absence of efficient protection and unique tourism products, the west scenic area in Changbai Mountain fails to get further development. Nowadays, with great economic situation and sharp increase in demands, it should adhere to the principle of "Protection First", develop burgeoning and unique tourism products like adventure tourism, cultural tourism with themes and vacation tour, as well as improve infrastructure and attract talents, in order to provide better service and make tourists get better tourism experience.

\section{REFERENCES}

[1] Cui Xiang, Zhou Lijun. Tourist Geography [M], Beijing: China Machine Press, 2006

[2] Liu Mingju, etc. Thinking on Research of Tourism Resources [J], Taxation and Economy, 2016(1)

[3] Li Wenhua. Tourism Planning of Changbai Mountain in Protection of Development Area, 2006

[4] Liu Mingju, etc. Research on Sustainable Development of Tourism in North Scenic Area of Changbai Mountain [J], Taxation and Economy, 2015(5)

[5] Ai Guisheng. Tourism Service Guide of Changbai Moutain [M], Beijing: China Travel and Tourism Press, 2013
[6] Xing Lixin. Origin of Landscape in Jinjiang Canyon of Changbai Mountain and Tourism Resources [J], Geological Review, 1999, (8) 